\title{
Growing Wheat and Vegetable Crops on Medium Composed of Olive Mill Wastewater, Pomace, and Limestone
}

\author{
Orwa Houshia ${ }^{1}$, Hazem Sawalha ${ }^{2}$, Anan Hussein ${ }^{3}$, Nael Abo $-\mathrm{Hasan}^{4}$, Aseel Turkman ${ }^{4}$, Rana Deeb $^{4}$, Salam \\ $\mathrm{Hamad}^{4} \&$ Samah Abo-Ilaya ${ }^{4}$ \\ ${ }^{1}$ Department of Industrial Chemistry, The Arab American University, Jenin, Palestine \\ ${ }^{2}$, Department of Biology, The Arab American University, Jenin, Palestine \\ ${ }^{3}$ Department of Physics, The Arab American University, Jenin, Palestine \\ ${ }^{4}$ Department of Biology and Biotechnology, An-Najah National University. Nablus, Palestine \\ Correspondence: Orwa Houshia, Department of Chemistry, Jenin, Palestine, E-mail: Orwa.houshia@aaup.edu
}

Received: February 26, 2019

Accepted: October 13, 2019

Online Published: October 17, 2019

doi:10.5539/mas.v13n11p54

URL: https://doi.org/10.5539/mas.v13n11p54

The research is financed by: $A A U P-D S R$, and FAO

\begin{abstract}
The main objective of this project is to develop sustainable method of innovative agriculture practices that relies on reducing the liquid and solid waste generated from olive mill and limestone slurry by-product from factories in Palestine. The second aim is to use these waste by-products in a proper ratio mixture and their feasibility in the agricultural use for optimal and best conditions. The overall output is the implementation of applied research on wheat crop and solanaceous vegetables including tomato and pepper which proved their tolerance to grow well in such natural medium. It was observed that the best mixing ratio of the two parameter of limestone slurry and OMW was at 90:10 respectively. Crop growth, plant length and leaf area were measured. The best ratio of lime to OMW in wheat and pepper was 90:10, while tomato 80:20. It appears that the best result including plant height and leaf surface area were obtained at 90:10 mixing ratio of limestone and OMW as medium of limestone, pomace and OMW was suitable for cultivating the different types of studied crops. In general, the best results of plant growth were achieved when the percentage of limestone was high in the medium. The research has shown that it is possible to prepare an alternative media for plant growth from three major environmental by-products that were considered pollutants. In general, as the percentage of limestone increased in the medium, the plants grow proportionally. Selection of project site was within the AAUP Biology department and arboretum
\end{abstract}

Keywords: limestone slurry, olive mill wastewater, pomace, agriculture crops, zeebar

\section{Introduction}

The olive oil extraction process produces liquid waste called olive mill wastewater (OMW) which is produced during the harvest season. OMW is a mixture of vegetative water and soft tissues of the olive fruit and the added water used in the various stages of the oil extraction process. The composition of OMW of which consists of $83-94 \%$ water, $4-16 \%$ organic compounds and $0.4-2.5 \%$ mineral salts and it depends on olive variety, the ripeness of the fruit, and the extraction process (press or centrifuge) (Cabrera et al., 1996: Lopez \& Ramos-Cormenzana, 1996).

The annual OMW production of the Mediterranean olive growing countries is estimated to amounts ranging from seven to over thirty million $\mathrm{m} 3$ (Niaounakis et al., 2004). In the West Bank, olive mills generate about 200 thousand m3/year of OMW (Subuh, 1999).

Recent research revealed that OMW is a major source of environment pollution in the Mediterranean region. In Palestine, an amount of $1.7 \mathrm{~m} 3$ /ton of OMW is found to be high compared to those amounts in other places of the world which requires technical review at the technology and operation of olive mills (El-Khatib, 2009). Wastewater from the different olive mills located in and around different villages in Palestine is being disposed of into the valleys, where it rolls with the untreated flowing municipal wastewater or with rainwater. The resulting high organic polluted wastewater affects soil and water receiving bodies (Shaheen, 2007). In addition, 
OMW has negative impact on agricultural crops and wild flora due to its acidic nature with large amounts of proteins, polysaccharides and mineral salts (Gocer et. al. 2017).

On the other hand, limestone is considered as pollutant for the environment. Natural and natural stone industry generates large volume of stone waste is basic in nature $(\mathrm{pH} \sim 9)$. Stone slurry is a semi-liquid substance consisting of particles originated from the sawing and polishing processes and water used to cool and lubricate the sawing and polishing machines. These generated wastes cause environmental, health and economical drawbacks (Mishra et. al. 2004). In Palestine, stone slurry has devastating effect on air quality, surface and ground water as well as its pollution to agricultural soil. Also, the calcium carbonate of slurry can accumulate in ditches and on soil surface forming cemented layer that prevents water infiltration and root growth. (Al-Joulani and Salah 2014, Al-Joulani 2008). In Palestine, liquid slurry is produced in amount of 750,000 cubic meters in the West Bank and 185,000 cubic meters of dry one which is produced by pressing the liquid slurry (Al-Joulani and Salah 2014).

Pomace (Jeft) is one of the solid residues of olive oil industry that consists of four main components: extractives, hemicelluloses, lignin (polyphenols), and mainly carbohydrate (specifically cellulose) and considered as pollutant. In Palestine, olive industry produces about 55000 tons of pomace waste annually (Musalam et. al. 2017).

The main goal for this research is sustainable development method to reduce the negative environmental impact of these pollutants and to use them in agricultural purposes. Therefore, mixtures of OMW, stone slurry and pomace were used to prepare medium for culturing crops. Three crops were used, including wheat (Triticum aestivum), tomato (Solanum lycopersicum), and pepper (Capsicum annuum). In addition, to find out agricultural natural soil, which is considered as alternative one to the non-productive soil in Palestine which is considered two third of the total land area of the country (Dudeen 2001).

\section{Method}

\subsection{Sample Collection}

Pomace and OMW were collected from automated olive mill factory uses three-phase centrifugal extraction method from Jenin governorate. Stone slurry was obtained from stone quarries established in Jenin governorate.

\subsection{Medium Preparation}

For medium preparation, OMW and limestone were mixed in different ratios shown in Table 1. The mixture together with $500 \mathrm{gm}$ each of pomace was added to the first nine pots and $500 \mathrm{gm}$ of pomace was added to each one of these nine pots. The other pots represent control sample by which they contain sand, sand with fertilizer, and sand with limestone for the tenth, eleventh and twelves respectively as shown in table 1.

Table 1. Percentage of mixing the OMW and limestone to make the medium

\begin{tabular}{ccccc}
\hline Pots № & limestone $(\mathrm{gm})$ & OMW $(\mathrm{ml})$ & Normal soil & Fertilizer \\
\hline 1 & 10 & 90 & - & - \\
2 & 20 & 80 & - & - \\
3 & 30 & 70 & - & - \\
4 & 40 & 60 & - & - \\
5 & 50 & 50 & - & - \\
6 & 60 & 40 & - & - \\
7 & 70 & 30 & - & - \\
8 & 80 & 20 & - & - \\
9 & 90 & 10 & - & - \\
10 & - & - & soil & - \\
11 & - & - & soil & Fertilizer \\
12 & 100 & - & soil & - \\
\hline
\end{tabular}

\subsection{Crop Planting}

Describe the procedures for selecting participants, including (a) the sampling method, if a systematic sampling plan was used; (b) the percentage of the sample approached that participated; and (c) the number of participants 
who selected themselves into the sample. Describe the settings and locations in which the data were collected as well as any agreements and payments made to participants, agreements with the institutional review board, ethical standards met, and safety monitoring procedures.

\subsubsection{Vegetative Growth Measurement}

Plant growth was evaluated by measuring the vegetative growth including plant height and leaf surface area. Leaf surface area was measured using the tracing technique according to Ferris et. al. 2001. Paper replica of the surface was compared with the standard data using the following equation:

Leaf area $(\mathrm{mm} 2)$ = weight of leaf tracing $(\mathrm{g}) \mathrm{x}$ conversion factor $(\mathrm{mm} 2 \mathrm{gm}-1)$. The measurements were done weekly for each plant sample.

\subsubsection{Statistical analysis}

Analysis of data was done using the Two-Sample Test of Proportion (TSTP). The results were analyzed using a level of significance when $\alpha=0.05$ (Montgomery 2008).

\section{Results and Discussion}

The result showed that medium of limestone, pomace and OMW was suitable for cultivating the different types of studied crops. Thus, the best results of plant growth were achieved when the percentage of limestone was high in the medium. Therefore, increasing the limestone percentage revealed positive and different encouragement effect of plant growth.

In addition, increasing the limestone percentage caused increased in plant height and leaf surface area. This may be attributed to alkalinity of limestone slurry which neutralizes the acidity of OMW. Similar results were obtained by Ghosh (2014) who reported that adding limestone causes neutralization of acidic soil and attains desired $\mathrm{pH}$ level of soil that maximizes plant growth.

Many researchers have established that these wastes have a high fertilizer value when applied to the soil; OMW is known to increase soil organic matter and the concentration of essential inorganic elements for plant growth resulting in enhanced soil fertility (Bonari et al., 1993, Cabrera et al., 1996 and Paredes et al., 1999).

\section{Wheat}

Regarding wheat, the results showed that all prepared ratios of natural medium and wheat cropping gave good growth. However, the best result including plant height and leaf surface area were obtained at 90:10 mixing ratio of limestone and OMW as shown in figure $(1 \& 2)$.

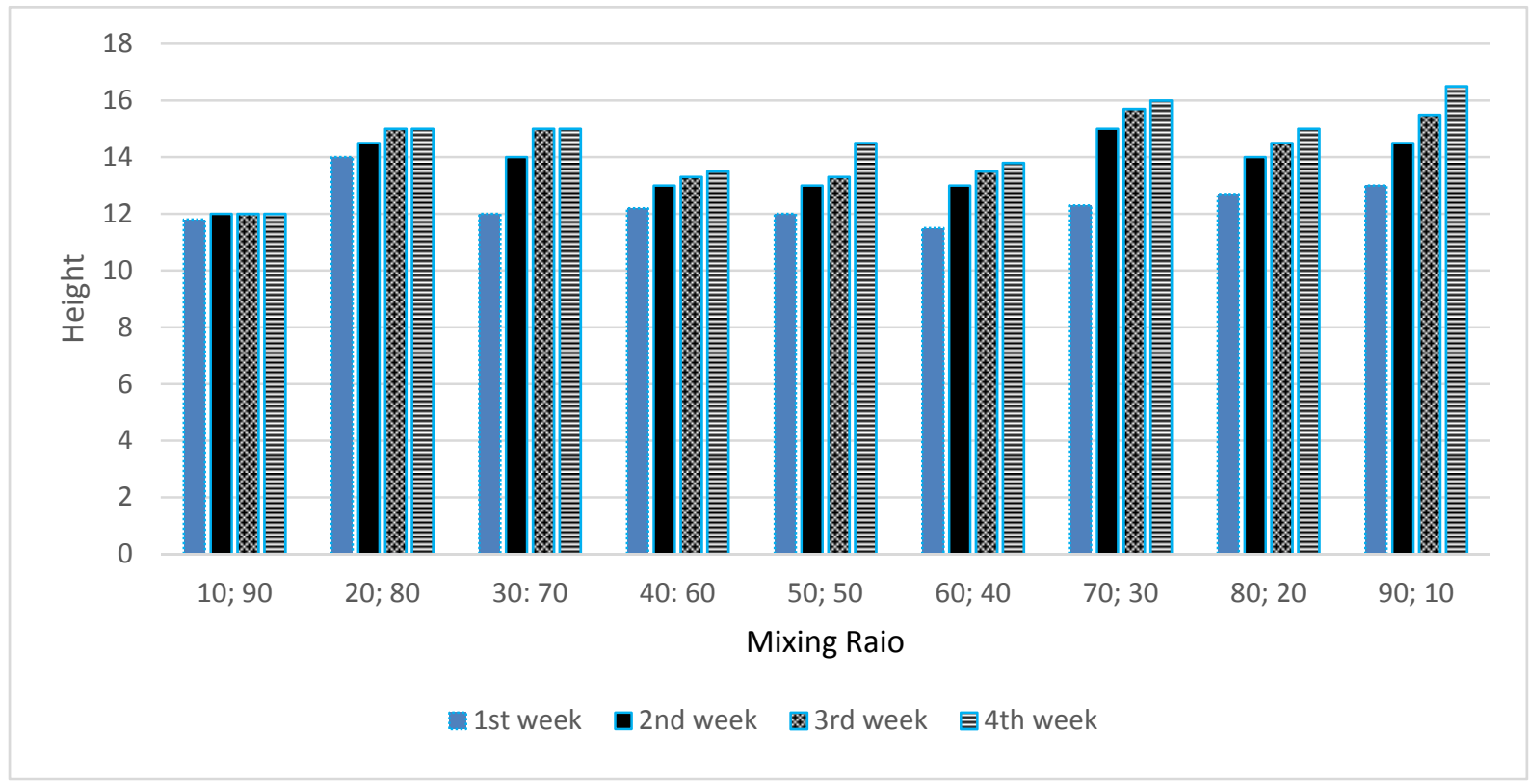

Figure 1. Wheat height $(\mathrm{cm})$ grown in the natural medium

*Letters above columns indicate treatments with significant difference 
As illustrated in figure 1 and 2, and as a consequence of increasing the amount of limestone in the mixture of the natural medium, a positive effect on plant growth and leaf area was observed. This is evident within the mixing ratios of $70 \%, 80 \%$ and $90 \%$ of limestone. Nevertheless, some positive growth was also observed at lower ratios, but the plant health was less desirable than the plants at higher ratio of limestone. This situation may be attributed to the ability of wheat to resist acidic condotions. In such regard, it was reported that wheat has the ability to resist low $\mathrm{pH}$ when grown at $\mathrm{pH}$ 3.0. The roots showed a good degree of alkalization and the shoot became more alkaline or remained unchanged (Budagovskaya 1995).

In addition, tomato plants showed a great sensitivity to all mixtures that are used in preparation of the natural medium. Mixtures with high amount of OMW (10:90-60:40) (limestone: OMW) caused drastic reduction in the plants growth during the first five weeks. Starting from the mixture of (70: 30), plants grew in a significant manner with time until the fifth week. The mixture of $(90: 10)$ showed the best plant growth with much significant difference between the first and the fifth week. However, the ratios of 90:10 and 80:20 showed the best plant growth (Fig 3, 4 \& 5).

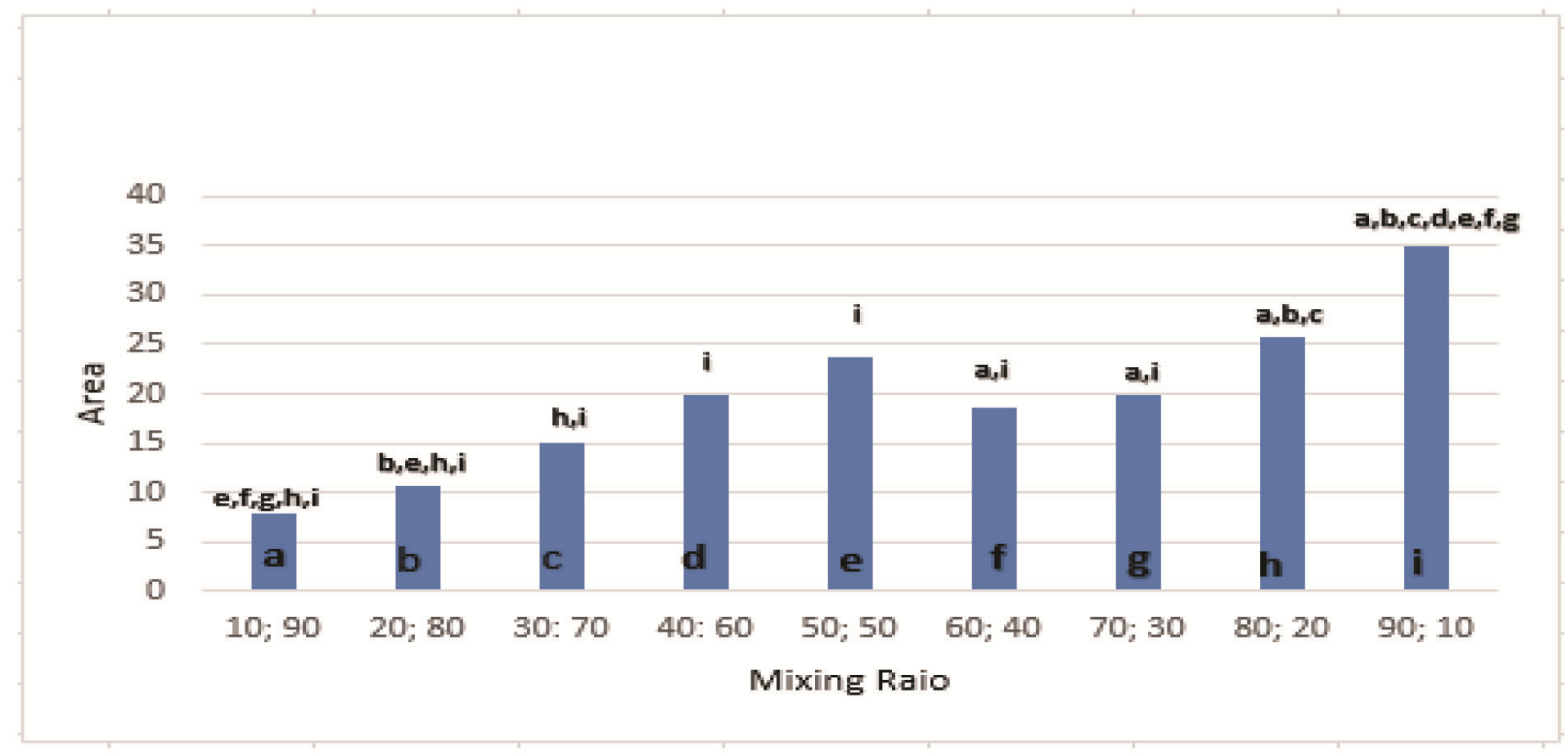

Figure 2. Wheat leaf surface area (cm square) grown in the artificial medium

\section{*Letters above columns indicate treatments with significant difference.}

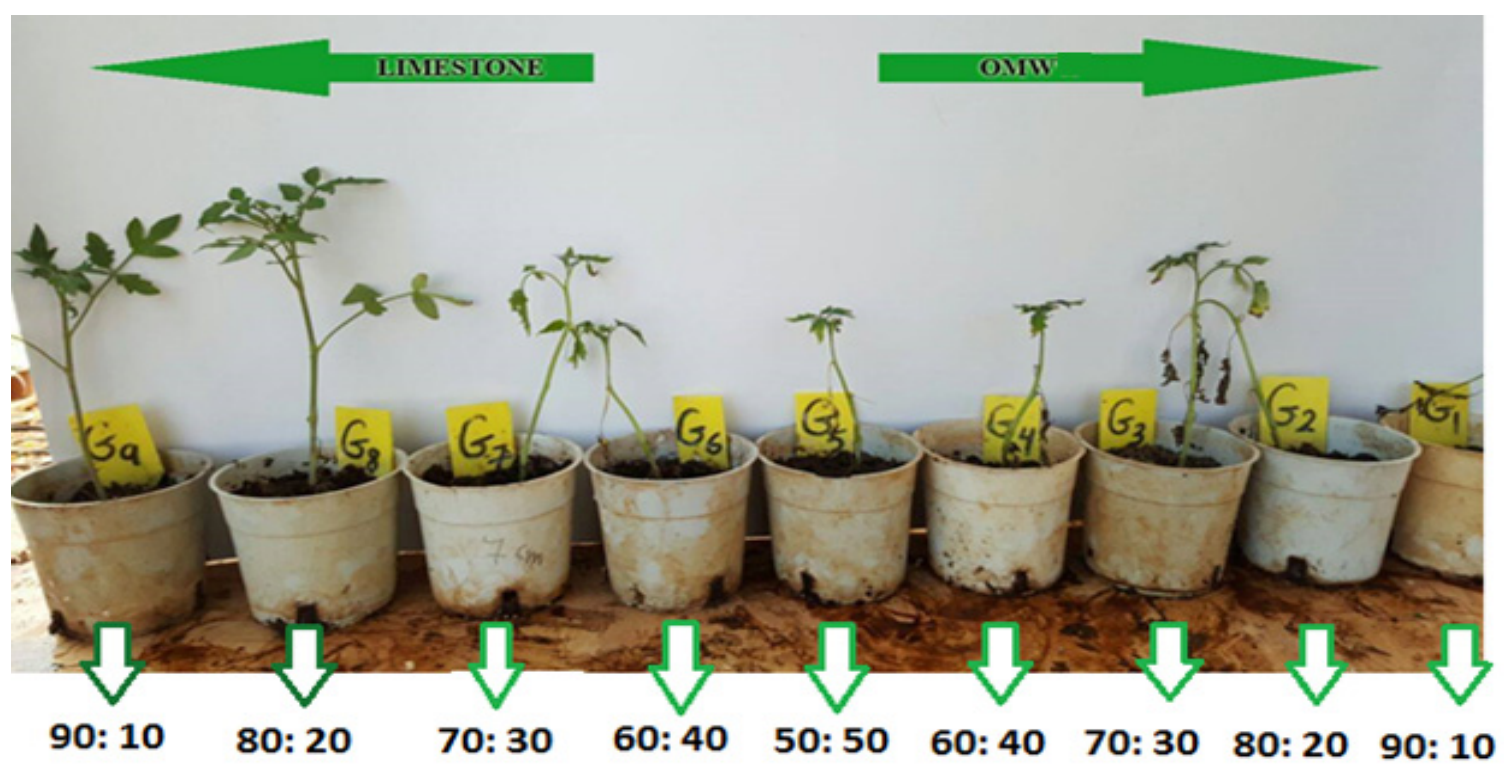

Figure 3. Tomato growth as a function of mixing ratios of limestone and OMW 
Tomato plants growth showed a drastic and obvious behavior and difference in growth on the natural medium than wheat and pepper. As shown in Figure (4), it can be inferred from the histogram that during the life span of the tomato plants, an astounding growth was observed for the $80 \%$ and $90 \%$ limestone. Such case may be due to the sensitivity of this crop to acidic pH. In this regard Wang et. al. (2000) reported that the growth of tomato plants was seriously affected by the soil acidity and lowering of uptake of elements was observed for the plants cultivated on acidified soil. At $\mathrm{pH}$ less than 4-5, the solubility of nutrients such as iron (Fe), aluminum ( $\mathrm{Al})$ and manganese (Mn) rises into toxic level that toxifies plant in different levels (Salaredini 1977, Hojhabrian 2014).

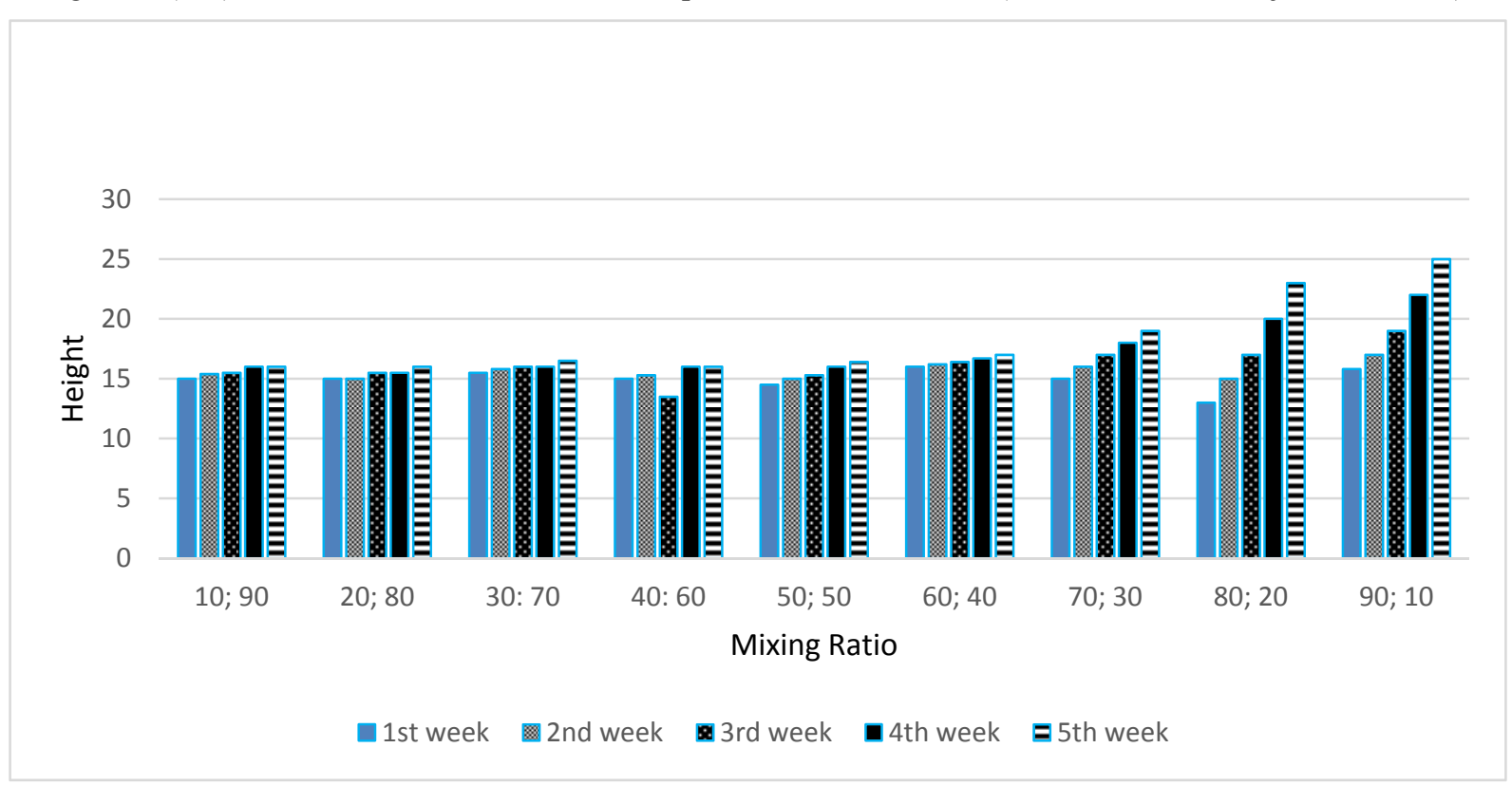

Figure 4. Tomato height $(\mathrm{cm})$ grown in the natural medium

*Letters above columns indicate treatments with significant difference

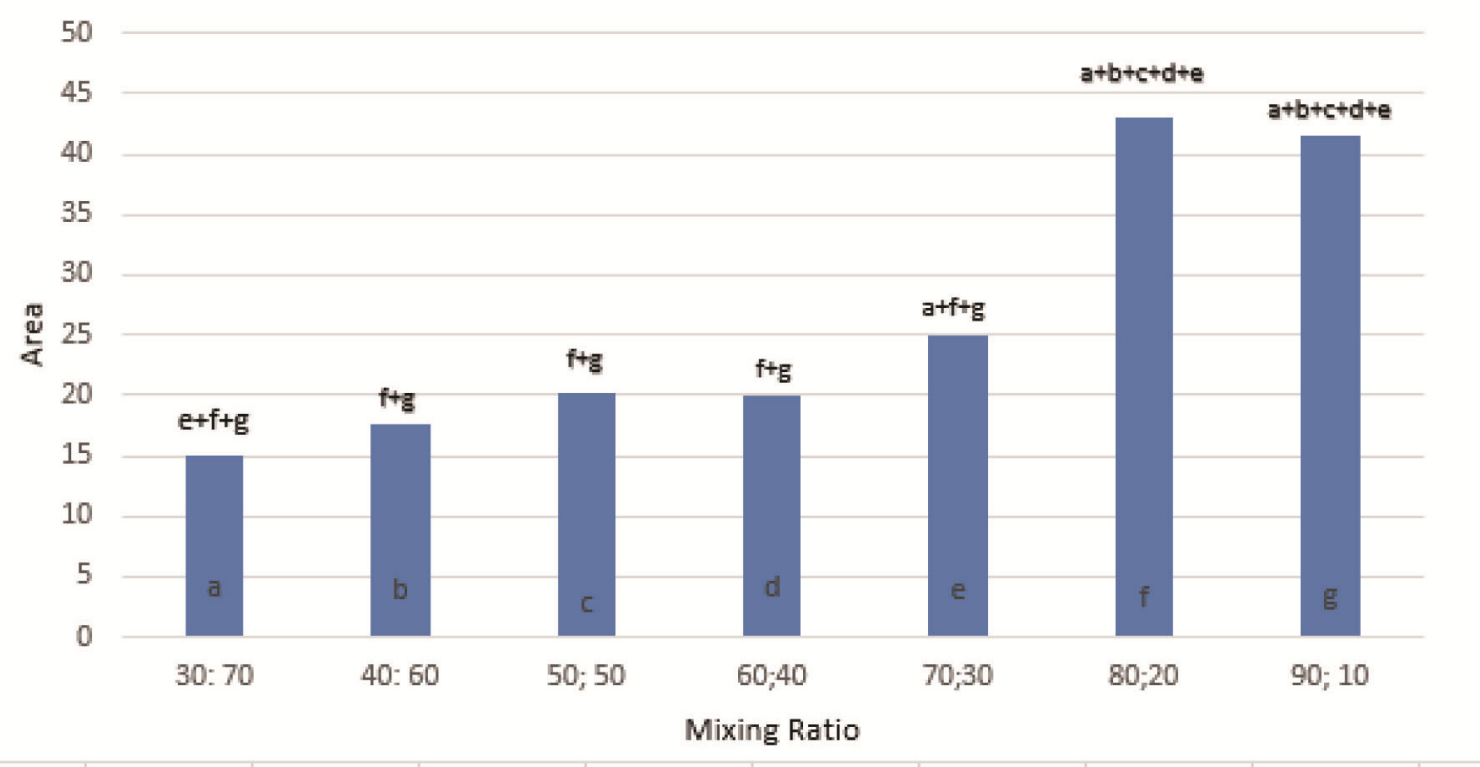

Figure 5. Tomato leaf surface area (cm square) grown in the artificial medium

\section{*Letters above columns indicate treatments with significant difference.}




\section{Pepper:}

Pepper plants grew well in all mixtures of natural medium (Fig 6, $7 \& 8$ ). Significant difference in plant growth was attained starting from the first week except the first treatment with $90 \%$ of OMW. The best mixtures that encourage plant growth were achieved starting from (70:30) of limestone and OMW (Fig 7). The plants showed much tolerance to the natural medium compared with tomato. However, the pepper growth was vivacious regardless of the mixing ratio of limestone. Pepper can grow adequately in $\mathrm{pH}$ media that ranges from $5.5-6.5$

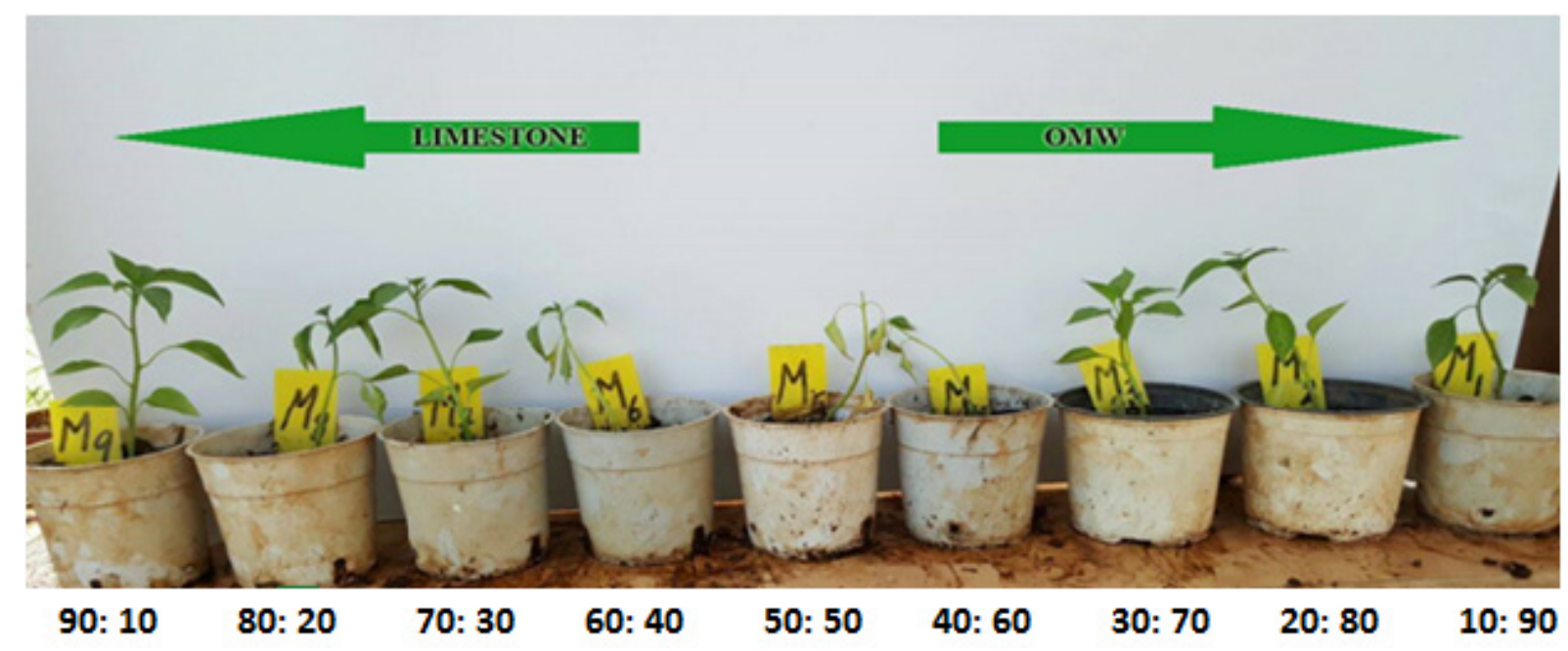

Figure 6. pepper growth as a function of mixing ratios of waste components

(Devasahayam et. al. 2015) and can grow in alkaline conditions (Amirinejad et. al., 2017). That might explain why the growth of pepper was active in most mixing ratios of natural media regardless to acidity of OMW (Achak et al. 2009), and alkalinity of limestone (Anderson et. al. 2013). The same trend of pepper growth on the natural medium was similar to the other test plants.

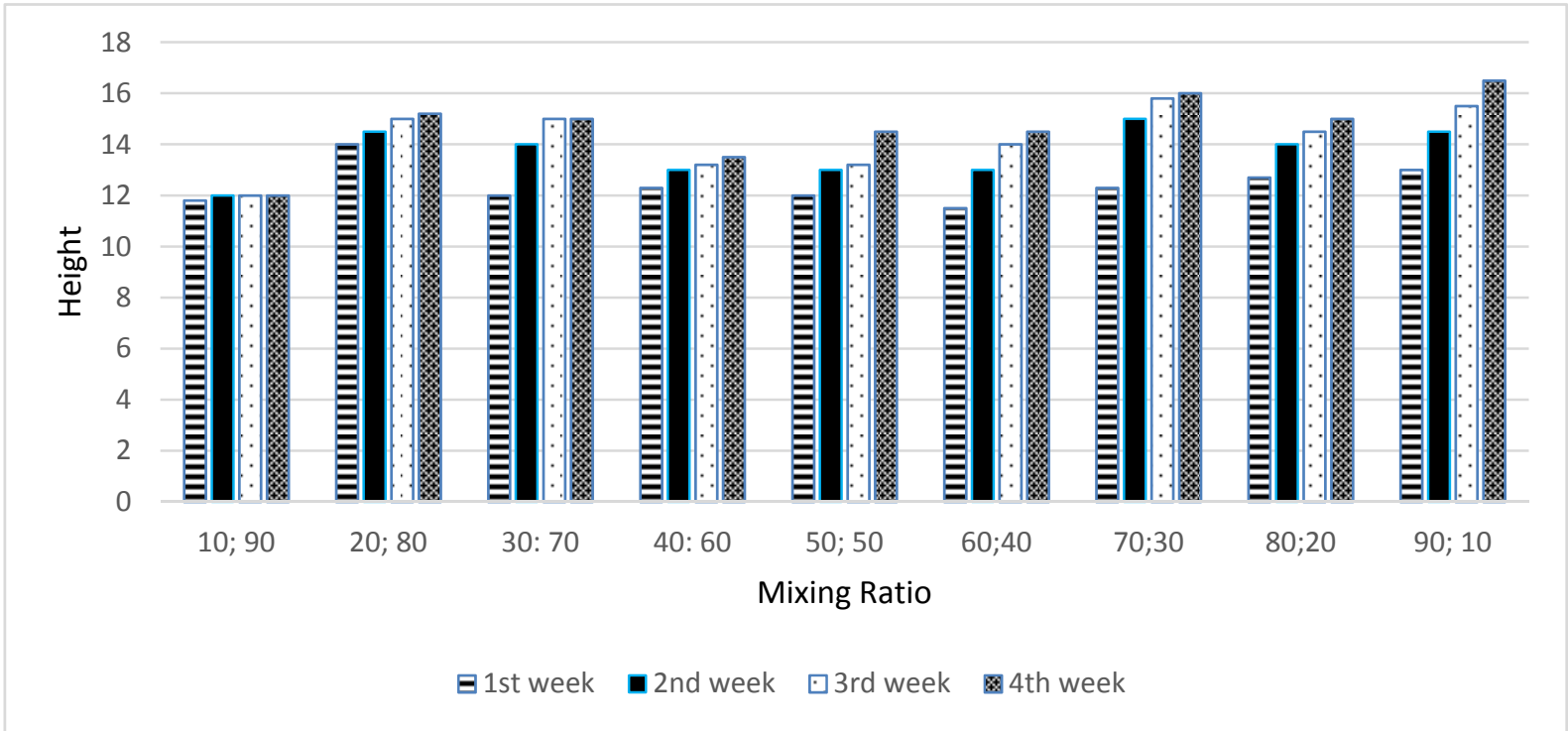

Figure 7. Pepper height $(\mathrm{cm})$ grown in the natural medium

*Letters above columns indicate treatments with significant difference. 


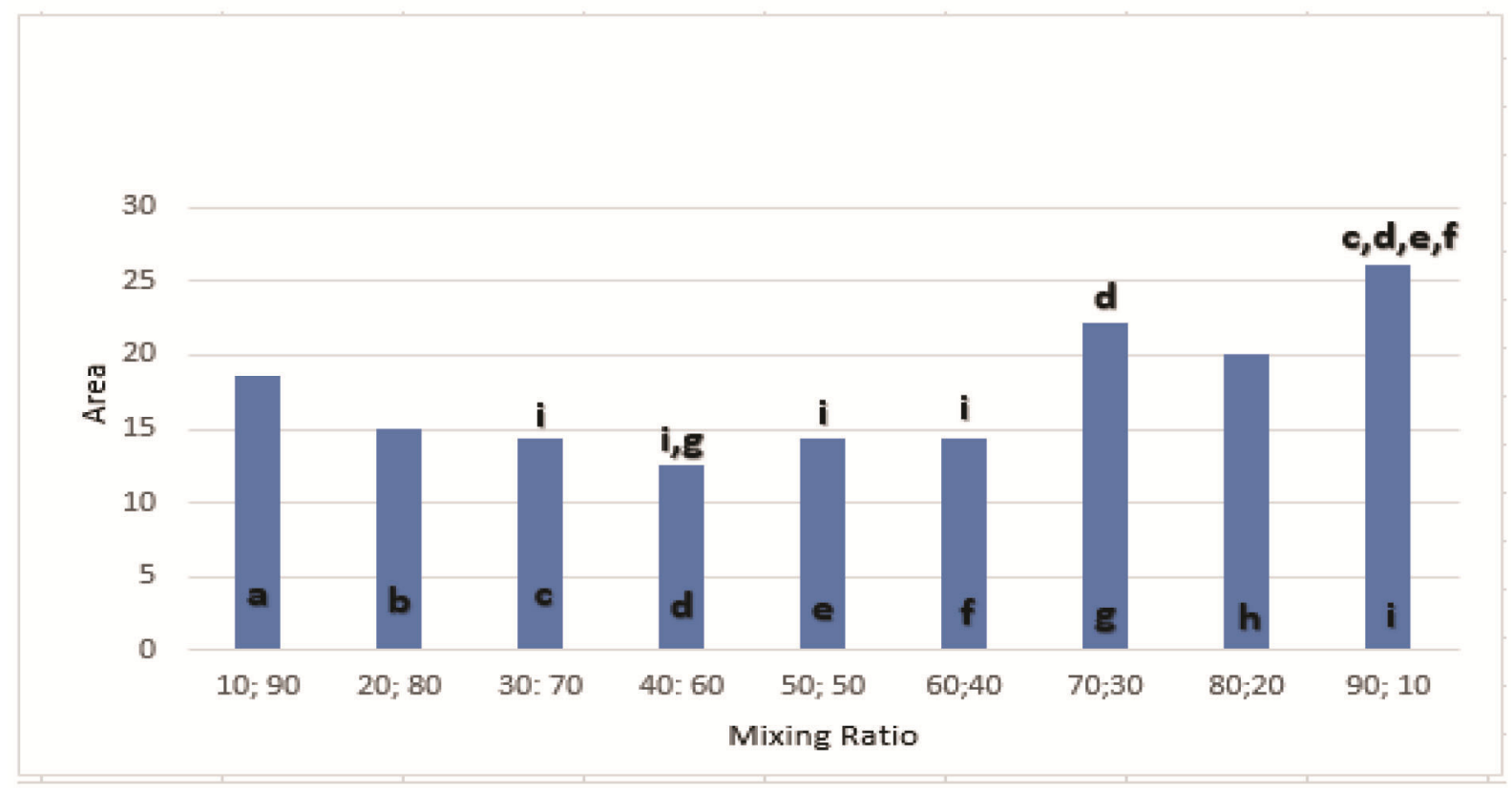

Figure 8. Pepper leaf surface area (cm square) grown in the artificial medium

*Letters above columns indicate treatments with significant difference.

\section{Conclusion}

The research has shown that it is possible to formulate a natural media for plant growth from three major environmental pollutants. As evident by the results pepper and wheat, growth was best for the most of mixing ratio, but the tomato was selective and sensitive to this medium. This media can be further studied for different other plants. In general, as the percentage of limestone increased in the medium, the plants grow proportionally.

\section{References}

Achak M, Mandi L \& Ouazzani N (2009). Removal of organic pollutants and nutrients from olive mill wastewater by a sand filter, J. Env. Manage, 90, 2771-2779. https://doi.org/10.1016/j.jenvman.2009.03.012

Al-Joulani, N. (2008). Soil Contamination in Hebron District Due to Stone Cutting Industry, Jordan Journal of Applied Science, 10, 37-50.

Al-Joulani, N. \& Salah, N. (2014). The Stone Slurry in Palestine from Environmental Burden to Economic Opportunities-Feasibility Analysis, Journal of Environmental Protection, 2014, 5, 1075-1090. https://doi.org/10.4236/jep.2014.512106

Amirinejad, A., Sayyari, M. Ghanbari, F. \& Kordi, S. (2017). Salicylic acid improves salinityalkalinity tolerance in pepper (Capsicum annuum L.), Adv. Hort. Sci, 31(3), 157-163.

Anderson, N., Hart, J., Sullivan, D., Christensen, N., Horneck, D. \& Pirelli, G. (2013). Applying Lime to Raise Soil $\mathrm{pH}$ for Crop Production (Western Oregon). OSU Extension Catalog. https.//catalog.extension.oregonstate.edu/em9057

Budagovskaya, N. (1995). Physiological state of shoots and roots and of energy transformation systems in plants at low pH. R.A. Date et. al. (eds.). Plant Soil International at Low Ph, 379-383, (C1995 Kluwer Academic Publishers. https://doi.org/10.1007/978-94-011-0221-6_57

C. Paredes, J. Ceggara, A. Roing, M.A. Sánchez-Monedero \& M.P. Bernal (1999). Characterization of olive mill wastewater (alpechin) and its sludge for agricultural purposes, Bioresource Technol, 67(1999), 111-115. https://doi.org/10.1016/S0960-8524(98)00106-0

Cabrera, F., López, R., Martinez-Bordiú, A., Dupuy de Lome, \& E., Murillo, J.M., (1996). Land treatment of olive oil mill wastewater. Int. Biodeter. Biodegr, 38, 215-225. https://doi.org/10.1016/S0964-8305(96)00054-6

Devasahayam, S., John Zacharaiah, T., Jayashree, E., Kandiannan, K., Prasath, D., Santhosh, J., Sasikumar, B., Srinivasan, V. \& Suseela Bhai, R. (2015). Manager, Agricultural Technology Information Centre ICAR- 
Indian Institute of Spices Research Kozhikode, 1.

Dudeen, B. (2001). The soils of Palestine (The West Bank and Gaza Strip) current status and future perspectves. In. Zdruli P.(ed.), Steduto P.(ed.), Lacirignda C.(ed.), Montanarella L. (ed.), Soil resources of souther and Eastern Meditranian countries Bari, CIHEAM, 2001, 203-225.

E. Bonari, M. Macchia, L.G. Angelini \& L. Ceccarini (1993). The waste waters from olive oil extraction. their influence on the germinative characteristics of some cultivated and weed species, Agric. Med., 123(1993), 273-280.

El-Khatib, F. Aqra, AL-Jabari M., Yaghi N., Basheer S., Sabbah, B. ALHayek I. \& Mosa M. (2009). Environmental Pollution Resulting from Olive Oil Production, Bulgarian Journal of Agricultural Science, 15(6), 544-551, 2009.

Ferris, R., Sabatti, M., Miglietta, F., Mills, R. \& Tylor, G. (2001). Leaf area is stimulated in Populus by free air CO2 enrichment (POPFACE), through increased cell expansion and production, Plant, Cell and Environment, 24, 305-315. https://doi.org/10.1046/j.1365-3040.2001.00684.x

Ghosh, I. (2014). The effect of limestone on soil and water.California State Science Fairp. Ap2/14.

Gocer, S., Eskikaya, B., Kozak, M., Duyar, A., Akgul, V., Akman, D. \& Cirik. K. (2017). Optimization of acid cracking method of olive mill wastewater pre-treatment acid cracking method for olive mill wastewate, International Journal of Advances in Science Engineering and Technology, 5, 1-4.

Hojhabrian, M. (2014). Effect of different soil pHs on the growth and proceeds of Tomatoes, Journal of Novel Applied Sciences, 145-147.

Lind, D., Marchal, W. \& Wathen, S. (2005). Statistical Techniques in Business \& Economics, twelfth edition, McGraw-Hill Irwin, New York, 262-263.

Lopez, M. \& Ramos-Cormenzana, A. (1996). Xanthan production from olive-mill wastewaters, Int. Biodeter. Biodegr, 38, 263-270. https://doi.org/10.1016/S0964-8305(96)00059-5

Mishra, P., Sahu, H. \& Patel, R. (2004). Enivironmental pollution status as a result of limestone and dolomite mining-a case study, Polution Research, 23, 427-432.

Montgomery, D. (2008). Design Analysis of Experiments, 7th Edition, John Wiley \& Sons. 60-98.

Musalam, A., Qaraman, A. \& El-Hassayna, I. (2017). Thermal properties of pomace olives in a compsite mixture, IUG Journal of Natural Studies, 25(2), 191-197.

Niaounkais, M. \& Halvadakis, C.P. (2004). Olive-Mill Waste Management. Literature Review and Patent Survey, 1 st edition, Athens, Typothito George Dardanos, 407.

Salaredini AA. (1977). Soil fertility. Tehran University, Iran, 44.

Shaheen, Hafez \& Abdel Karim, Nidal. (2007). Management of Olive Mill Wastewater in Palestine, An - Najah Univ. J. Res. (N. Sc.), 21.

Subuh, Yousef. (1999). Anaerobic treatment of olive mills wastewater using Up-flow Anaerobic Sludge Blanket (UASB) reactor. (Unpublished M.Sc. Thesis), Water Research. An-Najah N. University, Nablus, Palestine,

Tomati, U. \& E. Galli (1992). The fertilizing value of wastewater from the olive processing industry. Dev Agric, Manage.for Ecol, 25, 117-126. https://doi.org/10.1016/B978-0-444-88980-5.50015-X

Wang, H., Takematsu, N. \& Ambe, S. (2000). Effects of soil acidity on the uptake of trace elements in soybean and tomato plants, Appl Radiat Isot, 52(4), 803-11. https://doi.org/10.1016/S0969-8043(99)00153-0

\section{Copyrights}

Copyright for this article is retained by the author(s), with first publication rights granted to the journal.

This is an open-access article distributed under the terms and conditions of the Creative Commons Attribution license (http://creativecommons.org/licenses/by/4.0/). 